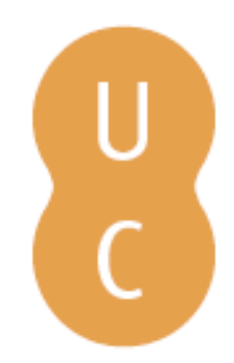

\title{
pommalina
}

\section{Terapia e transfiguração: notas sobre o filosofar em Wittgenstein}

\author{
Autor(es): $\quad$ Soares, Maria Luisa Couto
}

Publicado por: Imprensa da Universidade de Coimbra

URL

persistente: URI:http://hdl.handle.net/10316.2/32231

DOI: $\quad$ DOI:http://dx.doi.org/10.14195/978-989-26-0361-2_6

Accessed : $\quad$ 26-Apr-2023 12:30:02

A navegação consulta e descarregamento dos títulos inseridos nas Bibliotecas Digitais UC Digitalis, UC Pombalina e UC Impactum, pressupõem a aceitação plena e sem reservas dos Termos e Condições de Uso destas Bibliotecas Digitais, disponíveis em https://digitalis.uc.pt/pt-pt/termos.

Conforme exposto nos referidos Termos e Condições de Uso, o descarregamento de títulos de acesso restrito requer uma licença válida de autorização devendo o utilizador aceder ao(s) documento(s) a partir de um endereço de IP da instituição detentora da supramencionada licença.

Ao utilizador é apenas permitido o descarregamento para uso pessoal, pelo que o emprego do(s) título(s) descarregado(s) para outro fim, designadamente comercial, carece de autorização do respetivo autor ou editor da obra.

Na medida em que todas as obras da UC Digitalis se encontram protegidas pelo Código do Direito de Autor e Direitos Conexos e demais legislação aplicável, toda a cópia, parcial ou total, deste documento, nos casos em que é legalmente admitida, deverá conter ou fazer-se acompanhar por este aviso.

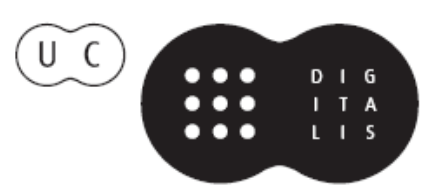


Diogo Ferrer

Coordenação

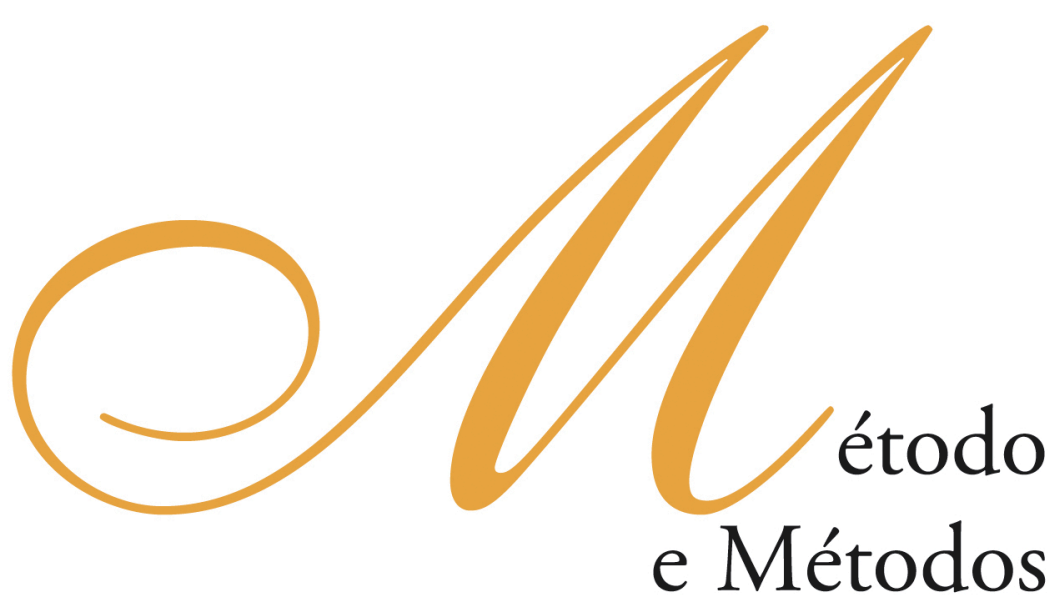

do Pensamento Filosófico 


\section{COORDENAÇÃO EDITORIAL \\ Imprensa da Universidade de Coimbra}

URL: http//www.imp.uc.pt

\section{CONCEPÇÃO GRÁFICA}

António Barros

PRÉ-IMPRESSÃO

Victor Hugo Fernandes

EXECUÇÃO GRÁFICA

Inova - Artes gráficas

ISBN

989-8074-02-7

DEPÓSITO LEGAL

$257236 / 07$

(C) Março 2007, Imprensa da Universidade de Coimbra

OBRA PUBLICADA COM O APOIO DE:

Centro de Estudos Clássicos e Humanísticos

FCT Fundação para a Ciência e a Tecnologia MINISTÉRIO DA CIÊNCIA E DA TECNOLOGIA 
Diogo Ferrer

Coordenação

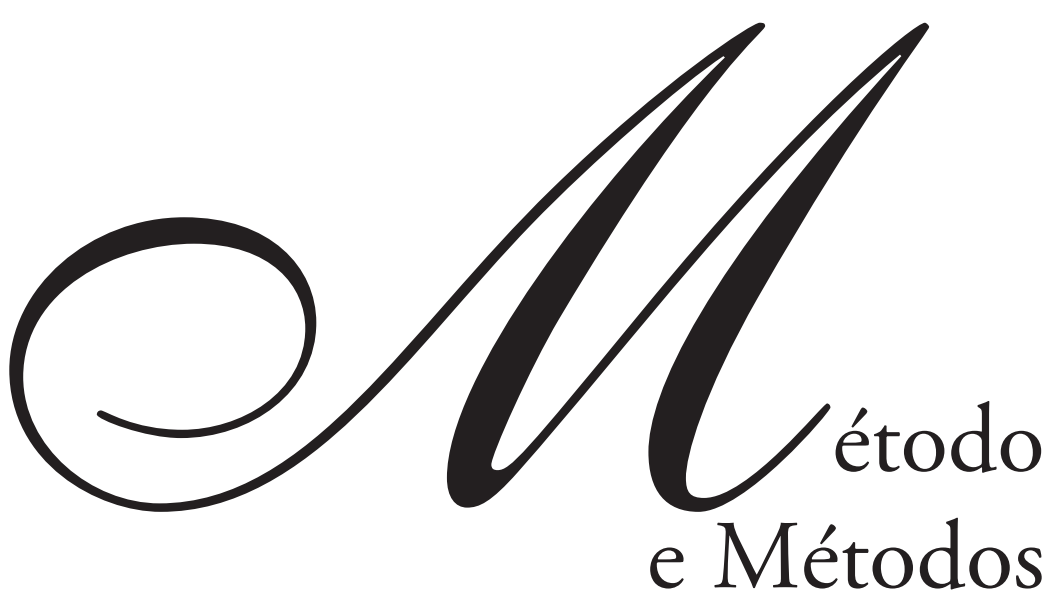

do Pensamento Filosófico

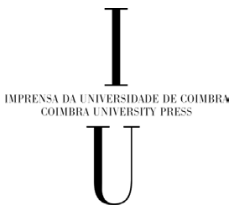

- COIMBRA 2007 



\section{Maria Luisa Couto Soares}

Universidade Nova de Lisboa

Terapia E Transfiguração

Notas SObRe O FILOSOfar EM WitTgenstein

Nós nunca nos realizamos. Somos dois abismos - um poço fitando o céu. Bernardo Soares, Livro do Desassossego

No princípio da Divina Comédia, Dante encontra-se extraviado numa selva escura "porque a direita via era perdida». Boécio abre a sua Consolação da Filosofia lamentando-se, mergulhado em lágrimas e tristeza, da sua pobre vida cruel e abençoa a morte que não sobrevem nos doces anos de paz, mas que traz o alívio ao coração alquebrado. E Riobaldo, na excelente obra de Guimarães Rosa, Grande Sertão, Veredas, exclama reiteradamente: «Viver é muito perigoso!» Não se referia apenas aos perigos escondidos na selva amazónica, mas à vulnerabilidade da vida humana. Viver é perigoso porque em cada momento, em cada situação, o homem joga-se a si mesmo e à sua liberdade. O risco da escolha e da decisão é constante, mas mais perigoso ainda será a indecisão, na qual se afogam a reflexão e o juízo, frustrados num fechamento inibidor.

Perdidos, extraviados, na selva do mundo e da nossa própria escuridão interior, a quem podemos recorrer? Dante encontra no meio da sua confusão a figura de Beatriz - "uma senhora tão beata e bela/chamou-me e que mandasse lhe pedi.» Boécio é confortado e encorajado pela própria Filosofia: 
a origem do seu mal e de ter caído na desilusão e na fraqueza da mente, vem do esquecimento de si próprio; mas não é dificil recuperar a memória, promete-lhe a misteriosa figura de mulher, desde que a reconheça como sabedoria. Riobaldo tem em Diadorim o companheiro certo e atento, a todas as horas: "Diadorim e eu, a gente parava em som de voz e alcance de olhos, constante um não muito longe do outro. De manhã à noite, a afeição nossa era duma cor e duma peça (...) Tão certo de si, ele repousava qualquer mau ânimo.»

«Onde é que nos encontramos?» pergunta-se Emerson. "Numa série da qual desconhecemos os extremos e julgamos que não tem nenhuns (...) Todas as coisas flutuam e reverberam... A nossa vida não está tão ameaçada como a nossa percepção. Como fantasmas deslizamos pela natureza, e desconhecemos sempre o nosso lugar." Em que nos podemos ancorar, no meio da corrente da vida que corre rápida, veloz e por vezes tormentosa? As perturbações profundas e a desorientação que nos envolve poderá encontrar algum ponto de mira que nos reconcilie com o mundo em que vivemos?

Estas vozes de desorientação e extravio de Dante, Boécio, Riobaldo, Emerson, assemelham-se ao modo como Wittgenstein exprime a natureza de um problema filosófico, que arranca de um "Não me sei orientar», "Não encontro o caminho...»(1). Se estivermos placidamente depostos no nosso mundo, nada nos parecerá surpreendente nem misterioso. Só nos aparecerá problemático se nos pusermos questões para as quais não encontramos respostas nesse mundo em que vivemos. E como sair então da situação aporética?

A convicção reiteradamente expressa por Wittgenstein é a de que os problemas filosóficos não se resolvem, não podem encontrar uma saída numa solução determinada e final. Não compete à filosofia resolver problemas,

(1) Cfr. Philosophical Occasions, p. 181: «O problema filosófico é uma consciência de desordem nos nossos conceitos, e pode ser resolvido pondo-os em ordem». 
apenas mostrar uma via para os dissolver ${ }^{(2)}$. Tanto o Tractatus como as Investigações Filosóficas têm em comum a mesma posição em relação às chamadas proposições filosóficas: são sem sentido (ou porque são $a$ priori, ou porque derivam de algum jogo de linguagem, ou porque lhes falta algum outro requisito), e por isso devem ser abandonadas, postas de parte, não lhes dar qualquer uso. São construções feitas com base em certas analogias, modelos ou imagens da nossa linguagem, que nos iludem completamente e nos induzem uma forma de mitologia encantatória mas falsa (3). Considerá-las sem sentido significa excluí-las de tal modo das nossas vidas que já não possam perturbar-nos mais ${ }^{(4)}$. A exclusão implica primeiro reconhecê-los, diagnosticá-los, encontrar-se com o problema; a solução virá de uma passagem a rejeitá-lo, a livrar-se dele, não pela busca de uma solução, mas transformando o nosso modo de viver de forma que deixe de constituir motivo de perturbação.

"A maneira de resolver o problema que vês na vida é viver de um modo que faça que o que é problemático desapareça».

"O facto de a vida ser problematica mostra que o contorno da tua vida não encaixa no molde da vida. Portanto, deves modificar a tua maneira de viver e, logo que a tua vida se encaixe no molde, o que é problemático desaparecerá»(5).

O Wittgenstein do Tractatus exprime exactamente esta ideia da filosofia como uma libertação, na qual a lógica desempenha o papel fundamental, tal como em Frege e antes dele, em Kant. A Lógica deve ensinar-nos a pensar correctamente, de modo que o nosso entendimento se encontre em harmonia

(2) Cfr. Philosophical Occasions, p. 18, 183: "Tal como entendo a filosofia, toda a sua tarefa consiste em me exprimir de tal modo que certas perturbações//problemas//desapareçam (Hertz)». "Se tenho razão, os problemas filosóficos devem ser completamente resolúveis, ao contrário de todos os outros". "Os problemas dissolvem-se no verdadeiro sentido da palavra - como um torrão de açucar em água.»

(3) Cfr. Cultura e Valor, p. 27: "A solução dos problemas filosóficos pode comparar-se com um presente num conto de fadas: no castelo mágico ele aparece encantado, mas se o vires no exterior, à luz do dia, não é mais do que um vulgar bocado de ferro...»

(4) Cfr. Diamond, C. - The Realistic Spirit, p. 35.

(5) Cultura e Valor, p. 47. 
consigo mesmo (6). O Tractatus pode ser entendido como a adopção cabal desta ideia kantiana de ver na lógica uma questão do acordo ou harmonia do entendimento consigo mesmo ${ }^{(7)}$ : se este acordo significa renunciar a qualquer proposição de tipo metafísico, a razão está em que nem Kant nem Wittgenstein, encontram um modo de enquadrar essas proposições no sistema categorial ou lógico-trasncendental que as tornariam possíveis. Por isso são impensáveis, embora isto mesmo não se possa dizer. São pura e simplesmente não-pensamento, portanto indizíveis.

Os problemas surgem de uma voz tentadora, que induz o leitor de Wittgenstein a teorizar, a tentar o impossível, dizer o que não pode ser dito, pensar o que não pode ser pensado. O estilo de Wittgenstein, particularmente nas Investigações, exprime-se num diálogo entre esta voz da tentação e uma voz da correcção que pretende reconduzir o leitor para a vida corrente ${ }^{(8)}$. Nem a voz que nos reclama para uma teorização lógica e lúcida, nem a que nos devolve para a vida normal, não problemática, se podem considerar expressões da perspcetiva real de Wittgenstein. São duas vozes de um diálogo mais amplo, no qual acabarão por se cancelar uma à outra. O objectivo dos diálogos de Wittgenstein consigo mesmo não é o de levar o leitor a uma teoria filosófica — nem uma teoria da linguagem ideal, sem fricções, nem uma teoria pragmática da linguagem corrente - mas sim o de ajudar a olhar através dos diversos modos de expressão e a conquistar uma nova sensibilidade, uma nova maneira de ver e de pensar.

O carácter prático, a finalidade ética da filosofia reside precisamente nisso: o seu desideratum é mudar a nossa maneira de viver até nos pormos

(6) Cfr. Kant, Logic, p. 16: Kant fala de mit sich selbst übereinstimmenden Gebrauch des Verstandes. O confronto é citado por Joan Weiner, Frege in Perspective Ithaca, 1990, cap. 2 e referido por Diamond, C., ob. cit., p. 29.

(7) Cfr. ibidem, p. 32.

(8) Cfr. Cavell, S. - "The Availability of Wittgenstein's Later Philosophy». Cavell atribui ao estilo das Investigações Filosóficas afinidades com os géneros de confissões e diálogos. O diálogo entre a tentação de formular questões para as quais não existem respostas, e a correcção ou dissolução do problema. Diálogo que devolve a paz à filosofia (cfr Investigações, 133), porque é a solução para o problema da vida (cfr Tractatus, 6.521-6.522). 
de acordo e em harmonia connosco próprios e com o mundo; encontrar modos de fazer com que tudo encaixe, dissolvendo os conflitos, os dilemas, as perplexidades; e ser capaz de parar quando se alcança um estádio de pacificação. A Filosofia é mais uma arte do que uma ciência ou um saber, uma arte de viver, uma ascese intelectual e moral que nos faça atingir a vida boa, excelente, o apaziguamento total das nossa dúvidas, conflitos, indecisões e perplexidades. O amor à sabedoria que não é a mera estagnação numa teoria, oferece um lenitivo para uma vida melhor, mais saudável e equilibrada e para uma pacificação dos desejos incontrolados e contraditórios que nos fazem soçobrar.

Este é o tópico de fundo da minha exposição: o carácter terapêutico da reflexão e do trabalho filosófico e a sua dimensão vital, existencial, como modus vivendi que mobiliza toda a forma de ser, de pensar e de agir. Poderia explorá-lo recorrendo a inúmeros exemplos - começando pelas escolas helenísticas, ou Pascal, Kirkegaard, etc. É recorrente a analogia entre a filosofia e a medicina. E é também recorrente considerar a filosofia mais como uma atitude vital do que como um mero saber teórico e descomprometido.

As grandes escolas helenísticas consideraram a filosofia como o grande remédio da alma; a medicina tem a capacidade de curar o corpo, a filosofia é a terapia da alma. A atribuição à filosofia de um poder terapêutico, e mais, a convicção prática de que é essa a sua principal finalidade, a de tratar e curar, não é exclusiva das antigas escolas filosóficas de Epicuro, dos estoicos, e cépticos da Grécia e de Roma, para as quais a filosofia é a autêntica arte da vida da alma. Em The Therapy of Desire ${ }^{(9)}$, M. Nussbaum explora a ideia de uma filosofia médica estudando o seu desenvolvimento nas três grandes escolas helenísticas - epícurea, estoica e céptica. O fito da terapia filosófica é alcançar uma vida excelente, garantida por uma total libertação de qualquer perturbação ou revolta, reduzindo a zero todos os vínculos a factores de instabilidade que ocorrem no decurso da vida humana. Nesta perspectiva,

(9) Sigo o I capítulo da obra de Nussbaum, «Therapeutic Arguments». 
a prática filosófica exerce particularmente uma acção que visa anular os desejos e emoções que alteram a quietude da alma e provocam distúrbios na comunidade social. Os argumentos filosóficos terão sempre um objectivo prático, dirigidos ao aperfeiçoamento do discípulo, dizem directamente respeito às necessidades e desejos do paciente e ao seu caso particular, à sua situação e necessidades. À semelhança da medicina, os argumentos terapêuticos são dirigidos à saúde do indivíduo, não a comunidades, o uso da razão prática é instrumental e não parte integrante do que é a própria vida humana boa e há uma nítida assimetria de papéis - o do médico e o do paciente, o da autoridade e o do discípulo. Uma diferença a notar: no argumento médico, o mestre não fomenta o escrutíneo dialéctico simpatizante com perspectivas alternativas nem encoraja o pluralismo cognitivo. Está fora do seu horizonte o confronto com outras possibilidades, a sua palavra tem a força de uma realidade que se impõe com toda a convicção. Se não fosse assim, perderia o seu poder curativo. Este procede em parte da segurança que gera eficácia na persuasão e é capaz de originar uma mudança no estado do paciente. No caso da terapia filosófica, o que se visa é precisamente o desprendimento de um ponto de vista próprio e o reconhecimento do seu carácter mítico. Corrigir o olhar significa conseguir olhar de outros modos, ver os diferentes aspectos, contemplar o mesmo objecto sob variados ângulos e perspectivas.

Os discursos terapêuticos não são apenas as elucubrações dialécticas que se propõem apresentar os diferentes lados e perspectivas de um problema. Pascal observa: o que nos causa vergonha, não é tanto a dificuldade para ver todos os lados da questão, para alcançar uma visão englobante e total, mas a hipótese de o nosso ponto de vista ser errado e estarmos, portanto, enganados. Naturalmente, o espírito não se pode enganar na perspectiva que considera sua, à qual está necessariamente ligado e que o impede de poder entrever outros pontos de vista. A dificuldade está precisamente em ter a capacidade de reconhecer outras perspectivas em alternativa à própria e de ver toda a gama dos possíveis pontos de vista que se podem apresentar. 
É necessário saber colocar-se no lugar do outro, para lhe mostrar que está errado; isso pressupõe a compreensão do modo como está a ver as coisas, abarcar o seu ponto de vista, reconhecer a sua verdade e mostrar-lhe outro lado pelo qual essa perspectiva é falsa ${ }^{(10)}$. A capacidade de persuasão passa pela capacidade de desprender-se de um ponto de vista único e ter a suficiente agilidade visual para olhar de diferentes modos e de diferentes ângulos.

No caso do argumento terapêutico, para conseguir a verdadeira conversão do olhar e para preservar a sua força persuasiva, ele deve apresentar uma perspectiva englobante, não simplesmente explicativa, mas convincente por ser mais ampla, mais rica e mais luminosa. A força da sua convicção procede, em parte, da sua inteligibilidade intrínseca, em parte da abertura intelectual e moral e do reconhecimento da amplitude de visão de quem o apresenta.

No entanto, esta situação de clarividência e de visibilidade alargada nem sempre é alcançável.

O filósofo é geralmente um homem situado e contornado por um mundo próprio: está sempre numa situação precária, indigente, com as debilidades intrínsecas à própria condição humana, condicionada pela dúvida, pela incerteza, pela ignorância, pelos limites das próprias capacidades. Tem uma visão difusa e obscura de tudo o que se passa à sua volta e não consegue abarcar tudo, apenas parcelas fugazes e truncadas. Se não fosse assim, viveria possivelmente numa situação de tranquila inconsciência e num adormecimento letárgico, com a felicidade própria da ignorância e da estupidez. Mas as realidades da vida humana são despertadores constantes que instilam a dúvida, a perplexidade e fomentam a curiosidade sobre si próprio. Se a nossa condição fosse verdadeiramente feliz, não seria necessário divertir-nos a pensar nisso - considerava Pascal. E a palavra divertir é neste caso a palavra-chave: pensar na nossa situação é com efeito um divertissement que pode servir de paliativo para a consciência da precariedade e indigência.

(10) Pascal, Pensées Pensées morales. 
Sócrates, no Teeteto fala de um sonho, não um sonho directamente sonhado, mas de um sonho narrado, que tem por fundamento um testemunho e assenta num «ouvir dizer»: é o sonho (ou a ilusão?), tão recorrente em filosofia, de atingir uma visão unívoca assente em pontos fixos e últimos, alicerces firmes de um edifício bem construído sobre bases inamovíveis. Porquê um sonho, não um mito? Pode interpretar-se o sonho como um ideal desejável mas inalcançável, um ponto atractor que regula todo o processo discursivo e analítico da razão; ou como a mera ilusão, a abdicação da razão que se abandona indefesa na região onírica, fora do domínio racional. Este ideal regulador ou ilusão transcendental é uma constante da história da razão humana e tem diversas expressões: exemplos múltiplos e em registos diferentes desse sonho são as mónadas de Leibniz, os objectos simples de Wittgenstein, os «indivíduos» de Russell, os protocolos e os sense data (na decomposição estrutural do processo cognitivo). O par simples/composto funciona como um atractor em diferentes domínios - do lógico ao epistemológico e ontológico e «<conduz> facilmente a toda a espécie de superstições filosóficas» $(11)$.

Até que ponto os nossos sonhos - sonhos sonhados, narrados, interpretados - revelam de facto o fundo dos nossos desejos mais íntimos, e podem ser encarados como aquela realidade oculta que mal se pressente e se faz ver através de pequenos sinais, vestígios da nossa própria profundidade inacessível? "Os sonhos parecem ter sempre algo de intrigante e, de um modo especial, interessante - e por isso queremos a interpretação deles. (São muitas vezes encarados como mensagens.)", comenta Wittgenstein a propósito de Freud(12). Em que consiste essa interpretação de um sonho? Em parte, como refere Wittgenstein, continuando a pensar em Freud, quando um sonho é interpretado, ele é integrado num contexto e deixa assim de ser intrigante. Este trabalho de interpretação pertence, de algum modo, ao

\footnotetext{
(11) Wittgenstein, Investigações Filosóficas, § 49.

(12) Aulas e Conversas, pp. 85 e ss.
} 
próprio sonho, é como sonhá-lo de novo ou prolongá-lo com as recordações de algo que aconteceu no dia anterior ou na infância remota. E parece que encontramos uma explicação para o sonho. Mas trata-se afinal, sempre do próprio sonho. Wittgenstein não reconhece a teoria pretensamente científica de Freud, que queria uma explicação que mostrasse o que é sonhar, queria encontrar a essência dos sonhos. Mas, de facto há uma grande variedade de sonhos que não é passível de ser subsumida por uma única explicação. Essa explicação pode ser atraente e levar-nos a aceitá-la porque nos satisfaz ou porque empresta uma certa lógica à desordem e desconexão das imagens dos sonhos. A atracção que essa explicação exerce não confere nenhuma evidência da sua correcção, nem nos leva a ver as coisas com um espírito mais lúcido. "É como comer o fruto da árvore do conhecimento", são palavras de Wittgenstein a propósito da psicanálise. Esse conhecimento, não só não resolve nada, como nos levanta novos problemas éticos ${ }^{(13)}$. No fundo, o que fazemos é simplesmente continuar a sonhar; ou recorrer a um mito para explicar outros mitos... Não será afinal o sonho uma transfiguração da realidade e a realidade uma transfiguração do sonho?

\section{Entre o sonho e a vigília}

O que Wittgenstein procura, para conseguir ver as coisas com a lucidez da vigília e simultaneamente com a magia do sonho — realidade transfigurada — é uma «visão panorâmica», uma «visão sinóptica». A experiência do que se conquista com a perspicácia conceptual nesta trasnformação dos modos de olhar é uma réplica da passagem do sentir-se perdido e desorientado para o encontrar-se a si mesmo. Mas esta estratégia exige um esforço de contenção para não situar-se precipitadamente numa posição falsa ou pelo menos numa

(13) Cfr. Cultura e Valor, p. 58 
perspectiva parcial. A dieta que nos devemos impôr é a da "não pretensão", segundo a expressão de Cavell, entendendo por isso a prudência intelectual para não nos comprometermos com afirmações espúreas ou apressadas. "O contexto do filósofo é de não-pretensão", escreve Cavell. O que significa esta não-pretensão? Cavell refere-se ao filósofo do conhecimento, que na sua investigação não encontra um solo suficientemente sólido que o possa dispensar de adoptar como estratagemas o recurso à imaginação de certos contextos. Para deixar em aberto a sua opção e a sua convicção, necessita de uma capacidade negativa, de contenção, de reconhecer que, de facto, nada descobriu de novo. (14)

Em filosofia, nenhuma explicação satisfaz completamente, nenhuma preenche o desejo de resposta. Quando as razões se acabam, resta o silência, depara-se com os limites da razão analítica, atarefada na sua acção de decomposição, de redução. Mas o silêncio não é total, porque é então que tudo se revela ser como é. A filosofia é simultaneamente analítica e intuitiva, discursiva e expressiva. O método - o método de Wittgenstein — consiste precisamente numa luta esforçada e contínua para não se deixar aprisionar por nenhum método: «O nosso próprio método é o da apresentação sinóptica (Übersicht). Tudo o que parece ser uma explicação é, de facto já falseado e não poderia satisfazer-nos totalmente."

Uma visão de conjunto (übersichtliche Darstellung)(15), uma visão sinóptica, não é a mera reprodução ou refiguração do status quo, nem o resultado de uma intuição, única e definitiva, mas exige reiteração do olhar, insistente e clarificador. Uma das metas do trabalho filosófico de Wittgenstein é precisamente a de alertar para os perigos de uma intuição apressada, que se satisfaz com uma visão aparentemente definitiva.

(14) Cfr. Cavell, S. - Les voix de la raison, pp. 326-330.

(15) Cfr. Philosophical Occasions, pp. 174-75: «Esta visão sinóptica produz apenas aquela compreensão que consiste em "ver as conexões». Daí a importância dos casos intermediários //de descobrir casos intermediários.» 
«Não penses, olha!», recomenda Wittgenstein nas Investigações. É o modo de olhar, não de pensar, que pode remediar a ignorância filosófica.

"A importância da descrição filosófica consiste no facto de nos permitir uma visão de conjunto que nos previne contra a adopção de um outro sistema unicamente pela razão que nós não vemos qual o "bom» (das richtige) sistema. Desejamos uma apresentação sinóptica, isto é um sistema, não vemos o bom: somos levados pela linguagem ou por quaisquer circunstâncias, a pressupor um sistema falso, e é a filosofia que nos liberta (erlöst) propondo-nos a visão sinóptica correcta»(16).

E como é que se alcança esta visão sinóptica? Não basta uma explicação, que deverá sempre encontrar um termo e parar, reenviando portanto a algo que não se deixa explicar. Em última análise, no fim de qualquer explicação, encontramo-nos sempre com alguma forma de convenção ou estipulação, que pressupões uma interferência no curso das coisas e da vida. A filosofia - observa recorrentemente Wittgenstein - não pode interferir com o uso real da linguagem, com aquilo que é realmente dito. No fundo apenas pode descrevê-la, deixando tudo tal como está, sem tentar, em vão, dar qualquer fundamento. (17) A descrição — descrição da linguagem como medium para esclarecer os problemas filosóficos - é como a descrição de um jogo, clarifica as regras (18) segundo as quais falamos, nos exprimimos, empregamos as palavras na variedade dos seus usos e sentidos. Este descrever é mais um ir descrevendo que tem o efeito de uma luz que se vai intensificando pouco a pouco, fazendo ver com uma nitidez cada vez maior e mais precisa.

(16) Dictées de Wittgenstein à Waismann et pour Schlick, p. 63.

(17) Cfr. Philosophial Occasions, p. 176-77: «A Filosofia apenas põe tudo diante de nós, nem explica nem deduz nada."

(18) Cfr. ibidem, p. 172-73: "A dificuldade reside apenas em compreender como a instituição de uma regra nos pode ajudar. Como nos acalma depois de ter estado tão profundamente inquietos. Evidentemente, o que nos acalma é o facto de vermos um sistema que (sistematicamente) exclui aquelas estruturas que sempre nos inquietaram, com as quais éramos incapazes de fazer seja o que for, e que julgávamos mesmo assim que tinhamos de respeitar. A instituição de uma regra gramatical não será semelhante, neste sentido, à descoberta de uma explicação em física, por exemplo, do sistema copernicano? Há uma semelhança." 
Em nenhum momento se poderá recorrer decisivamente a uma verificação, que não permite estabelecer uma ligação entre a linguagem e o mundo: entre a linguagem e a realidade não existe qualquer termo intermediário. De facto, escreverá Wittgenstein, temos «O sentimento que com a linguagem não aderimos à realidade, porque o tempo escapa-se-nos enquanto falamos (...)». Sentimos que "os fenómenos nos escapam e desaparecem no passado sem que os possamos reter» (19). Teremos que contentar-nos com descrições particulares e aproximadas: "A descrição do meu campo visual, quer seja através de palavras, quer seja com o auxílio de um desenho, ou de qualquer outro modo, será sempre aproximada, bruta, imprecisa - cada uma à sua maneira. O melhor, mais uma vez, será não fazer nenhum enunciado geral, mas procurar no caso específico o que se poderia chamar como uma «maior exactidãom (20).

Dado este hiato entre linguagem e realidade, impossível de colmatar por um processo de verificação, ou por uma descrição "isomórfica", "pictórica», a única possibilidade é recordar o uso da linguagem(21). Não é possível fazer uma ideia exacta, correcta, deste carácter vago da linguagem que escapa a uma visão meridiana e nítida. Apenas logramos uma imagem nebulosa, de contornos esfumados. A linguagem "gira em torno das palavras como o ar à volta das coisas. É a luz do crepúsculo que banha a maior parte dos significados das palavras. Para pôr diante dos olhos este factor invisível e no entanto presente em todo o lado, desejaríamos esgotar-nos para encontrar imagens e metáforas (Gleichnisse).»(22) Ser capaz de bem metaforizar é um dom, que não pode ser aprendido de outros, mas requer o toque de génio; uma boa metáfora, já o dizia Aristóteles, pressupõe uma percepção intuitiva

\footnotetext{
(19) Dictées..., p. 161.

(20) Ibidem, p. 162.

(21) Ibidem, p. 59. Cfr. Philosophical Occasions, p. 172-73.

(22) Ibidem, p. 139.
} 
das semelhanças e das diferenças ${ }^{(23)}$. E não há como uma boa parábola para refrescar o entendimento $(24)$.

O método da filosofia, o modo de pensar os seus problemas é surpreendente, difícil e um tanto paradoxal. No Big Typescript (1933), Wittgenstein anota a dificuldade deste trabalho: «Dificuldade da filosofia não a dificuldade intelectual das ciências, mas a dificuldade de uma mudança de atitude. As resistências da vontade têm que ser superadas» E continua: «... O trabalho em filosofia é - como é frequentemente o trabalho em arquitectura - mais uma espécie de trabalho sobre si próprio. Sobre a sua própria concepção. Sobre o modo de ver as coisas. (E o que esperamos delas.)... O método da filosofia: a representação clara dos factos gramaticais/ /linguísticos. Objectivo: a transparência dos argumentos. Justiça.

$\mathrm{Na}$ impossibilidade de ver com nitidez, de obter uma imagem, representação, intuição definida das coisas e dos conceitos, temos de contentar-nos com uma pluralidade de imagens que se sobrepõem, se multiplicam numa aproximação assintótica de uma imagem mais exacta. O mais adequado será adoptar uma visão em constante movimento fazendo o esforço de ir focando para alcançar a boa perspectiva, o bom ponto de mira.

A atitude filosófica consiste numa luta constante para ver com claridade, sem se deixar aprisionar por falsas miragens, conceptualizações apressadas, generalizações empobrecedoras. Para compreender a essência das coisas - a essência da linguagem - não basta analisar, escavar com os recursos cognitivos, mas é necessário olhar e vislumbrar o que se esconde para lá da aparência: «...vê-se a essência, não como algo que está exposto já à luz do dia, e a que se pode dar um arranjo panorâmico, mas como algo que jaz debaixo da superfície, apenas no interior, aquilo que vemos quando o nosso olhar penetra através da coisa e que é suposto ser escavado pela análise. A essência está-nos oculta: é esta a forma que toma agora o nosso

\footnotetext{
(23) Cfr. Poética, XXII, 1459a9.

(24) Cultura e Valor, p. 13.
} 
problema» (25). Neste texto estão em contraste as "duas maneiras de pensar» de Wittgenstein: o "escavar» próprio do estilo analítico que dominou o afã de limpidez cristalina da linguagem lógica, e o "arranjo panorâmico» assente na convicção de que tudo o que é necessário está já à vista. A pretensão de descobrir algo mais, para lá do que um olhar perspicaz consegue ver, pressupõe o exercício de uma força despótica, que deforma as coisas tal como elas são: a análise conceptual pode tornar-se numa espécie de prisão que amarra a realidade expressa na linguagem numa grelha demasiado estrita e apertada, que deixa escapar as diferenças, numa atitude dogmática cega e obscura.

A dificuldade está na miopia que perturba o olhar e lhe impede o acesso a essa visão sinóptica que apreende os aspectos, mesmo os mais distantes (26). É fundamental a capacidade de descobrir aspectos, construindo casos ideais, «imagens gramaticais» à semelhança dos casos litigiosos que o jurista adopta como "paradigmas». Este procedimento implica repetições, que para uma nova geração parecerão maçadoras, mas para Wittgenstein são necessárias: cada frase é uma tentativa de exprimir tudo, ou seja, a mesma coisa repetidas vezes, "como se fossem visões de um mesmo objecto, obtidas de ângulos diferentes» (27).

É esta visão sinóptica que nos dá uma compreensão cuja originalidade reside no facto de nos permitir "ver as relações» (28) e descobrir os termos intermediários (Zwischenglieder) que salvam as cisões, aparentemente incontornáveis, de falsos dilemas. Isso exige reaprender a olhar, a fixar a atenção e descobrir novos modos de ver que projectem novas luzes sobre as coisas aparentemente anodinas. É o olhar humano que tem o poder de

(25) Investigações Filosóficas § 92.

(26) Cfr. Cultura e Valor, p. 13: «É difícil indicar um caminho a um míope, visto que não se lhe pode dizer: "Olhe para aquela torre de igreja a dez milhas daqui e siga nessa direcção.»

(27) Cfr. Cultura e Valor, p. 13 e 21.

(28) Cfr. ibidem, p. 27: «O pensador assemelha-se muito ao desenhador cujo objectivo é representar todas as inter-relações entre coisas.» 
conferir valor às coisas (29), apresentando-nos o mais vulgar e quotidiano - a nossa própria vida - como uma obra de arte feita por Deus, merecendo ser contemplada. Só o artista é capaz de apresentar assim uma coisa individual de modo que ela nos apareça como uma obra de arte e esta obriga-nos, por assim dizer, a vê-la da perspectiva correcta; fora dela o mesmo objecto parecer-nos-á um mero fragmento da natureza e será olhado com frieza, desinteressadamente(30). E uma investigação filosófica tem uma estranha semelhança com uma investigação estética. Como é que se vê um quadro? Não basta ver é necessário olhar: pode-se visualizar o todo de um só golpe, depois aproximar-se para fixar um e outro detalhe, uma cor, uma expressão, depois afastar-se de novo para apanhar uma nova perspectiva, reparar na luz que nele incide, nas sombras que o matizam, nas formas que sobressaem. A visão do quadro é caleidoscópica, feita de um conjunto infinito de olhares que se repetem no espaço e no tempo, se prolongam do presente para o futuro e abrem novos horizontes, confluem numa experiência estética que se vai reiterando e ampliando. Não há limites, nem temporais nem espaciais, a obra de arte exige repetição, é necessário voltar sempre a olhar uma vez e outra, a vivência permanece sempre em aberto, incompleta.

A dificuldade está no saber olhar, no descortinar o segredo da pintura. Tal como ao pensar um problema filosófico, é necessário encontrar as boas perspectivas, descobrir aspectos, rondar o quadro. E tanto o pensar como o olhar, são difíceis: é possível olhar com atenção e não ver nada, pensar concentradamente e não alcançar a claridade(31).

A filosofia, para Wittgenstein, consiste de facto num «trabalho sobre si mesmo", não um trabalho de introspecção, de uma dobra sobre si mesmo, mas de corrigir e suster o olhar, recuperar o modo originário e natural

(29) Cfr. Cultura e Valor, p. 13.

(30) Cfr. ibidem, p. 17 e 18.

(31) Cfr. Cultura e Valor, p. 110: «Pensar é difícil». Que significa isto realmente? Por que motivo é difícil pensar? - É quase como se dissesse: "Olhar é difícil» Porque olhar atentamente é difícil. E é possível olhar atentamente sem ver com clareza seja o que for. Olhar pode fatigar, mesmo quando nada se vê.» 
de olhar, desembaciando a nossa maneira habitual de ver as coisas(32). É precisamente sobre os «modos de ver e de olhar» que Wittgenstein trabalha, procurando a justeza de uma verdadeira "apresentação sinóptica» (übersichtliche Darstellung), que é o autêntico caminho do pensamento. Este, ora «voa sobre o mundo e o deixa tal como é - observando-o de cima, em voo»(33), ora se detém a examinar as coisas de perto, focando detalhes, olhando-as a partir de dentro, não à distância. A estratégia de Wittgenstein propõe frequentemente uma perspectiva dupla, que alterne entre uma visão do todo, à distância e uma cuidadosa observação das suas partes, dos elementos que o constituem. Entre o significado de «ver» e o de "pensar" há um comércio estreito, que torna difícil muitas vezes destrinçar os dois conceitos. Leiam-se os parágrafos das Investigações Filosóficas II, xi, nos quais as experiências visuais são exploradas detidamente, mostrando a complexidade que se esconde muitas vezes no uso desatento do verbo "ver», e as afinidades com o "pensar»: "... a iluminação súbita de um aspecto parece ser meio experiência visual meio pensar»(34). A compreensão da gramática do verbo "ver» não se compadece com uma abordagem de superfície que se deixe prender por disjuntivas excessivamente simples que não admitam termos médios: «Mas isto não é ven! — "Isto é ver»! - Ambas as expressões têm que se deixar justificar conceptualmente»(35).

O método de investigação assente na convicção da possibilidade de uma análise última, intimamente conectada com os pressupostos do Tractatus, é claramente posto de lado por Wittgenstein, que nas Investigações compara este estilo de pensar a alguém que tentasse encontrar a autêntica alcachofra arrancando-lhe, uma a uma, todas as folhas(36). Nalguns casos, os mal-

(32) Cfr. Cultura e Valor, p. 33

(33) Cultura e Valor, p. 18.

(34) Investigações Filosóficas, II, xi, § 33.

(35) Ibidem, II, xi, § 74 .

(36) Cfr. § 164. 
entendidos poderão dissipar-se com uma substituição de uma forma de expressão por outra, designando este processo como uma «análise» das nossas formas de expressão (37). Mas isto pode criar em nós o mito de uma clarificação total, «uma forma perfeitamente decomposta da expressão» - uma das teses em que assentava toda a lógica do Tractatus. Esse «Sonho da análise» é totalmente ilusório: julgamos que as nossas formas de expressão estão essencialmente por analisar, como se houvesse nelas algo oculto que necessitasse de ser esclarecido, reconduzido a um estado de exactidão perfeita(38). Não é essa a meta da «investigação gramatical»: esta não pressupõe conceitos absolutamente determinados, com fronteiras nítidas e exactas, mas move-se no terreno impreciso e vago da prática linguística e do uso corrente de expressões que cumprem a sua finalidade tal como se dão. O próprio conceito de jogo é um "conceito de contornos esfumados», uma «imagem difusa» que não é possível substituir por uma nítida; mas é muitas vezes a difusa que mais precisamos $(39)$. A ideia de que toda a proposição deve ter um sentido definido não passa de um preconceito que impede uma visão clara, como um par de óculos sobre o nariz, através dos quais vemos tudo, sem que nos ocorra nunca tirá-los $(40)$. Esta foi a prisão do ideal analítico que condicionou toda a visão do mundo à luz da lógica do Tractatus: o que Wittgenstein propõe é fazer rodar completamente o eixo da investigação, tomando como ponto de referência as nossas necessidades reais ${ }^{(41)}$. Para tal, não é a exactidão total que se deve procurar, expressa numa visão intuitiva terminal (Einsichtt) mas uma visão de conjunto (Übersicht) — «não ambiciono exactidão, mas uma visão sinóptica».

O primeiro ideal, perseguido no Tractatus, consistia em alcançar uma visão sub specie aeternitate - uma visão atemporal do todo, gloriosa, omnisciente

\footnotetext{
(37) Cfr. $\$ 90$.

(38) Cfr. § 91.

(39) Cfr. $\S 71$.

(40) Cfr. § 103.

(41) Cfr. § 108.
} 
e definitiva, que revelasse o que é o mundo, não o como é o mundo. Ver o todo significa ver a totalidade de conexões de cada objecto, a plena verdade das coisas que só a lógica pode proporcionar, numa perspectiva à distância, de fora, com o mundo todo como horizonte, na qual cada objecto é visto em conjunto com espaço e tempo, e não no espaço e tempo (42).

A visão sinóptica, panorâmica, que Wittgenstein procurará mais tarde, exige situar-se dentro do mundo, no meio dos conceitos e suas expressões, ao mesmo nível, em vez de fora deles, ou de algum modo, transcendendo-os. E é no meio do labirinto das ruas de uma cidade e dos caminhos tortuosos de uma floresta, que o filósofo tentará traçar «esboços paisagísticos» que exprimam os enredados processos, múltiplos e variados, da nova maneira de ver e de pensar.

Não se pode sair deste entramado de regras que nos orientam numa cidade. Podem parecer artificiais, estranhas, quando fazemos a experiência de as transcender, de nos abandonarmos na selva exterior regida pelas leis do desejo e das emoções, que nos dão uma visão fantástica da vida. Mas a vida não é o que parece. Nas suas notas das conversas com Wittgenstein, Bouwsma regista: "Na cidade, as ruas estão bem traçadas. E andamos pela direita, e temos semáforos nos cruzamentos, etc. Há regras. Quando saímos da cidade, continua a haver estradas, mas já não há semáforos. E quando vamos mais longe, já não há estradas, nem semáforos, nem regras, nada que nos guie. Não há senão bosques. E quando regressamos à cidade, podemos ter a impressão de que as regras são falsas, de que não deveriam existir regras, etc.» $(43)$.

A decifração da metáfora vem a seguir: "A cidade é a vida da acção exterior. Podemos dispor aí de guias simples. Mas fora da cidade há a força selvagem da natureza, os desejos, as emoções. E que faremos, então? E não será a cidade um lugar superficial?».

\footnotetext{
(42) Cfr. Notebooks, 7.10.16.

(43) O.K. Bouswma - Conversas com Wittgenstein, p. 81.
} 
Nestas notas de Bouswma podemos dar-nos conta do modo como Wittgenstein pensava e agia sobre os outros: o seu estilo de vida e de acção. Não era a preocupação por transmitir umas ideias, uma filosofia que fosse depois transformada por outros, reproduzida em segunda mão — "por que razão teria eu de ensinar? De que serve a este ou àquele ouviremme? Só um homem que pense pode tirar disso qualquer coisa de bom» —. As grandes ideias rodeiam-se em geral de uma auréola de incomunicação, de inefabilidade, não circulam com facilidade, são pensamentos pessoais... Mas estes mesmos pensamentos tendem à exteriorização, à comunicação, e nesta medida tornam-se públicos, comunicados e... impessoais. É extremamente difícil determinar o momento exacto em que os pensamentos pessoais assumem a forma da coisa pensada. Esta barreira invisível que separa o pensamento genuíno da erudição pesada e da ideia morta, era sem dúvida temida por Wittgenstein. Daí a sua resistência a «fazer escola», a rodear-se de discípulos ou a publicar os seus escritos. Musil escreveu que quando termina o acto de pensar, perde a forma sob a qual viveu, para assumir a da coisa pensada, forma que se torna impessoal, porque volta o pensamento para o exterior, destinando-o à comunicação. ${ }^{(44)}$

A sua seriedade, a intensidade de pensamento em Wittgnstein impediam-no de se perder em diálogos inúteis. O mais importante, confessa Bouswma, «era o facto de ele me arrancar ao conforto indolente da minha própria mediocridade». E reconhece que com Wittgenstein, foi descoberto um novo método que preenchia a sua esperança de encontrar enfim alívio, alimento e direcção. O novo método visa, não só uma articulação da própria identidade racional, auto-consciente com modos adequados de expressão - maior expressividade - como também a projecção de novas formas do viver em comunidade humana, na qual coexistem a liberdade expressiva e o reconhecimento recíproco ${ }^{(45)}$. A tarefa é árdua e apresenta duas dimensões

(44) Cfr. O Homem sem Qualidades, p. 134.

(45) Cfr. Eldridge, R. - Leading a Human Life. Wittgenstein, Intentionality and Romanticism, p.108. 
aparentemente opostas: desmantelar o edifício do nosso orgulho (46), suspeitar de todo o esforço intelectual isolado, que leva a seguir um caminho próprio, a andar pela sua conta, contra a corrente geral da cultura e civilização, por um lado; e ao mesmo tempo perseguir sempre uma maior e mais rica forma de expressividade, sem se conformar passivamente com a cultura tal como ela se apresenta. É o trabalho de toda uma vida. Não se pode confinar a um texto, ou a um livro, abarca todas as dimensões intelectuais, práticas, sociais que entretecem uma vida humana. É um processo de conversão contínua, de transfiguração. Emerson — Stanley Cavell aproxima-o de Wittgenstein no modo de ver a filosofia como um processo de conversão - caracteriza o pensar, precisamente por estes dois traços: conversão e transfiguração. Em duplo movimento: o da trasnformação de si mesmo e o da série de trasnformações - metamorfoses - que a palavra, o texto vai originar nos outros. A pretensão filosófica de Wittgenstein é a de ser um espelho no qual o leitor possa ver todas as disformidades do seu pensamento e, com essa ajuda, pô-lo em ordem ${ }^{(47)}$.

O projecto terapêutico de Wittgenstein aponta para uma possível cura: essa cura é a completa clareza que significa o simples desaparecimento dos problemas filosóficos. A verdadeira e única descoberta consiste, afinal, em encontrar a saída da filosofia, ou, em palavras de Wittgenstein, "a que me torna capaz de terminar o trabalho filosófico quando eu quero, de pôr a Filosofia em paz consigo própria, de modo a não ser fustigada por questões que a põem a ela própria em questão»(48). Aqui ouvimos uma das vozes (49) que intervêm no diálogo que Wittgenstein mantém consigo

(46) Cultura e Valor, p. 46

(47) Cfr. Cultura e Valor, p. 35.

(48) Investigações, § 133.

(49) Cfr. Cavell, S. - «Notes and Afterthoughts on the Opening of Wittgenstein's Investigations", p. 136: Segundo a leitura de Cavell as Investigações mostram que o que designa por vozes da melancolia e do júbilo, ou da metafísica e do corrente, da tentação e da correcção, se causam umas às outras e constituem um argumento sobre o qual não há que decidir, mas que é necessário desmantelar. Não representam variações meramente literárias do mesmo tópico filosófico ou intelectual, mas requerem uma indagação da própria polifonia. 
mesmo - "conversas privadas comigo mesmo. Coisas que a mim próprio digo face a face»(50) — a voz da vida, da clarificação, do júbilo. Mas há que ouvir também a outra voz — a voz tentadora da metafísica, da melancolia, da perturbação. Porque o pensamento de Wittgenstein assume de facto uma forma reiteradamente dialógica, a duas ou mais vozes, que se vão formando e transformando mutuamente, sem nunca se anularem nem confundirem totalmente. As dissonâncias que produzem vão construindo uma certa harmonia, mas uma harmonia feita de diferenças e variações: elas mostram, de facto a impossibilidade de exprimir os problemas filosóficas a uma só voz, de adoptar uma posição única e estável. As palavras finais do citado $\S 133$ das Investigações traduzem a perspectiva de Wittgenstein quanto ao método da filosofia: "Não há um método mas há da Filosofia, de facto, métodos, tal como há diversas terapias».

(50) Cultura e Valor, p. 114. 


\section{Bibliografia}

Bouveresse, Renée - "Wittgenstein et Freud», in Bouveresse-Quillot (org.), Visages de Wittgenstein, Paris, Beauchesne, 1995.

Bouwsma, O. K. - Conversas com Wittgenstein 1949-1951, Lisboa, Relógio D’Água, 2005.

Cavell, Stanley - The Claims of Reason: Wittgenstein, Skepticism, Morality and Tragedy, New York, Oxford University Press, 1979 (trad. fr: Les Voix de la Raison. Wittgenstein, le scepticisme, la moralité et la tragédie, Paris, Ed. Du Seuil, 1996.

"Notes and Afterthoughts on the Opening of Wittgenstein's Investigations", in Cavell, S. Philosophical Passages: Wittgenstein, Emerson, Austin, Derrida, Oxford, Blackwell, 1995.

Diamond, Cora - The Realistic Spirit. Wittgenstein, Philosophy and the Mind, Cambridge Mass, The MIT Press, 1995.

Eldridge, Richard - Leading a Human Life. Wittgenstein, Intentionality and Romanticism, Chicago and London, The University of Chicago Press, 1997.

Kenny, Anthony - Wittgenstein, Cambridge, Mass, Harvard University Press, 1977.

"Cartesian Privacy" in Pitcher, George, Wittgenstein: The Philosophical Investigations, Garden City, Hew York, Anchor Books, 1966.

"Wittgenstein on the Nature of Philosophy" in Wittgenstein and His Times, McGuiness, Brian (ed.) Chicago, University of Chicago Press, 1982.

Nussbaum, Martha - The Therapy of Desire. Theory and Practice in Hellenistic Ethics, Princeton, New Jersey, Princeton University Press, 1994.

Peterman, James F. - Philosophy as Therapy. An Interpretation and Defense of Wittgenstein's Later Philosophical Project, State University of New York Press, 1992.

Sluga, H. e Stern, David G. (Ed.) - The Cambridge Companion to Wittgenstein, Cambridge University Press, 1996.

Wittgenstein, L. - Investigações Filosóficas, Lisboa, Fundação C. Gulbenkian, 1987.

Notebooks 1914-1916, Ed. von Wright, G. H. e Anscombe, G. E. M. Oxford, Blackwell, 1961 (trad. port. Edições 70, 2004).

Dictées de Wittgenstein à Friedrich Waismann et pour Moritz Schlick, (org. A. Soulez), Paris, PUF, 1997.

Zettel, Anscombe, G. E. M. e von Wright, (Ed.) G. H., Oxford, Blackwell, 1967 (trad. port. Edições 70, 1989).

Philosophical Occasions 1912-1951 James Klagge e Alfred Normann, (Ed.) Indianapolis \& Cambridge, Hackett Publishing Company, 1993.

Wittgenstein's Lectures and Conversations, Oxford, Basil Blackwell, 1966 (trad. port. de Miguel Tamen, Ed. Cotovia, 1991).

Cultura e Valor, Lisboa, Ed. 70, 1996. 



\section{Série}

\section{Documentos}

Imprensa da Universidade de Coimbra

Coimbra University Press

2007

- U

C • 